\title{
Innovative digital technology design and game healing-Serious Game's innovative design for children with special needs
}

\author{
Yang Feng ${ }^{1 *}$ \\ ${ }^{1}$ College of Art Design Guangzhou Panyu Polytechnic, Guangzhou. China
}

\begin{abstract}
Digital technology promotes the innovation and development of design. With the development of science and technology, design has changed the traditional design mode. We must stimulate the innovative potential of design and let digital technology play a greater driving force.The current era of "internet of all things" is also a new challenge to the development of human civilization. Game design as an important part of modern design, its design innovation is worth thinking about: How to use the rapidly changing Science and Technology; how to organically connect the real world with the virtual world; how to skillfully integrate human care into the game design; how to use the game to pay attention to special groups; how to make the function of the game get multi-dimensional presentation and other aspects are worth discussing.
\end{abstract}

\section{INTRODUCTION}

Games have the characteristics of entertainment and relaxation. Games are becoming more and more integrated into all aspects of people's lives as human civilisation develops. In the current situation, where the concept of games is constantly being redefined, games are taking part in the processes of modern society in a more active way. As an important part of the game, functional games ${ }^{1}$ also bring spiritual comfort to special groups.

\section{The connection between Science and Technology and art, design and education}

Technology has been accompanied by the development of art, design and education, such as: The representatives of ancient Chinese science and technology and design are highly praised for ""Heavenly Creations", "Dujiangyan, bronze ware," Four Great Inventions" and so on. In addition to promoting the development of civilization, technology and commerce, Science and Technology also promote people to further understand the world, know each other and understand themselves. Since time immemorial, artists have explored and experimented with their means of expression, mediums, painting media, etc., all of which are linked to technology. Their ideology and creative thinking need scientific judgment and establish a connection with science. Science and Technology carries art, and art can also reflect the dimension of science. While printmakers explore the possibilities of ink and paper, ceramicists experiment with "kiln", and oil painters even worry about the ratio of the medium of expression ...... are real examples of the combination of technology and art. Art and science and Technology are the necessary conditions to realize the high unity of rational logical thinking and perceptual creative thinking.

The inseparability of science and technology from art and design has also been increasingly appreciated by the education sector. For example, in recent years, the Central Academy of Fine Arts has organised the "East Season" event, which aims to discuss the relationship between science and technology and art, as well as the relationship between science and education. East stands for Education, Art,Science and Technology, respectively. In November 2019, at the "3th East Season Opening Ceremony" and "The International Conference on Education, Art, Science and Technology" hosted by The Central Academy of Fine Arts, Su Xinping, Vice President of THE Academy of Fine Arts, proposed: The scientific research results of science and technology art directly serve national construction; the academic concept of science and technology art has been widely agreed in the art and academic circles; science and technology art is both humanistic and socially sensitive ......Martin Honzik, Director of the Ars Electronica Festival in Linz, Austria, also made the point that he wanted to gradually find new ways of connecting art and science and technology. Qiu Zhijie, President of the school of experimental art of the Academy of Fine Arts and initiator of the conference, proposed: "East Seaton" is
${ }^{1}$ functional games: Also known as serious games, Serious Game is using the concepts and methods of game design to combine learning and fun and present it to the user in a completely unique experience. [1] As early as 2004, the "US Serious Gaming Summit" presented functional games for military, educational and medical applications in the USA designed to help users to penetrate expertise in a fun and light-hearted atmosphere. According to Falstein N, the "father of the Serious Game", these games are personalised, interactive and entertaining, but they belong to the serious purpose of educating, training and treating the player. [2] Tencent and Netease have coincidentally announced the deployment of "Serious Game" in 2018, and have released a number of games based on traditional culture, such as "Nishan Shaman", "Ziyue Shiyun" and "Huizhen-Miaobi Qinashan". [3]

\footnotetext{
*Corresponding author: 19480739@qq.com
} 
an annual international academic activity of Science, Technology and art, and is also an International Alliance of Science, Technology and art education. He cites the concept of 'community-accelerated innovation', developed by Anderson, founder of the website Myspace, to encapsulate the qualities of the EAST Alliance. A special Children's Education Forum has also been set up at EAST SEASON 2020, putting science and technology education for young people on the agenda with the aim of integrating the art of science and technology education into the education of children and young people.

\section{Healing experience in digital games}

Spiritual healing is becoming more and more important with the development of technology and medical advances, and the arts are also becoming involved. The formation of the profession of art therapist and the emergence of therapeutic models of art education have provided some inspiration for other fields. The gradually developed and mature silver tail with the corresponding healing experience has also become an indispensable existence in digital games. The healing experience in digital games has also become an important basis for game developers. For example: Re-Mission, developed by HopeLab, an American Research institution, in 2006. Scientifically tested, it is a Serious Game that can effectively help young cancer patients to fight the disease. The results show that: Patients who played games showed significant improvements in cooperation with cancer treatment, efficacy and quality of life compared to those who did not play. By breaking through the 20 levels in the game one by one, patients learn what's going on in their bodies and learn how to fight cancer more effectively.
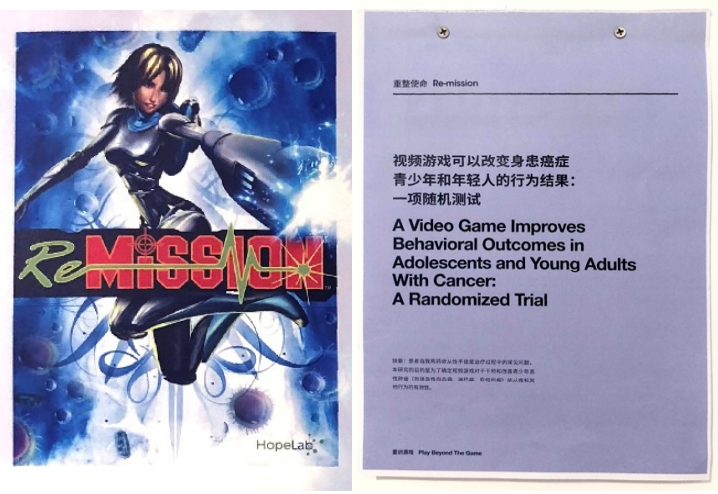

Figure 1: Game: Re-Mission and Game Randomized Trial [The picture is from the exhibition "Play Beyond The Game"]

At the first functional and game art exhibition in 2018, a space game designed for the spirit of ADHD children in 2013 by Dutch research firm heartburn ventures: Plan+It Commander, a game for children with ADHD (attention deficit hyperactivity disorder), is designed to train and expand the necessary life skills of ADHD children through carefully designed games. The GAME won the 2014 The Fun\&Serious Game award for best health GAME, the 2013 DUTVCH GAME AWARDS for best app game design, and the 2013 DUTVCH GAME AWARDS for best serious game. Plan-It Commander is a game jointly completed by a strong research and development teams, jointly developed by XBV, \&Ranj and Yulius. A Heartbeat Venture is made up of world-class serious game developers and entrepreneurs. They are all from research institutions and universities, they are top researchers. They aim to improve the lives of children with ADHD worldwide. \&Ranj is a professional serious game development organization, and behavioral intervention is their strong point. Yulius, whose full name is yulius academies, focuses on the research and innovation of mental health. Therefore, digital technology can greatly promote the dimension and depth of game healing. The spiritual cure is the higher cure, the real cure.

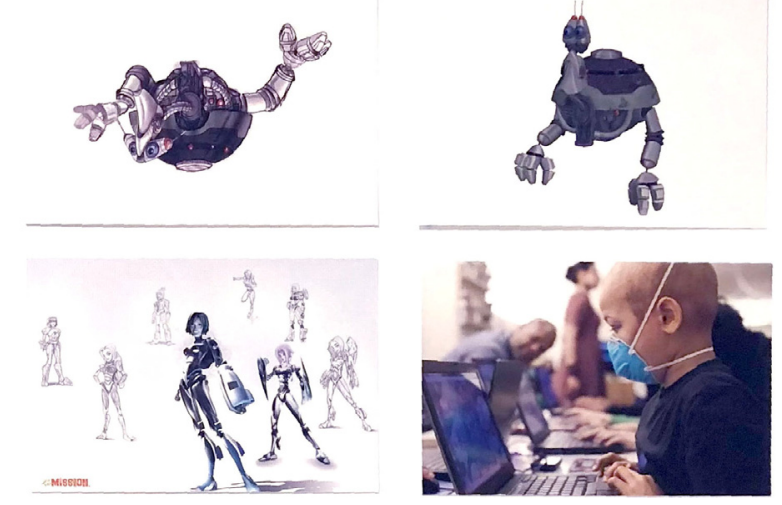

Figure 2: Game: Re-Mission [Game character and game scene]

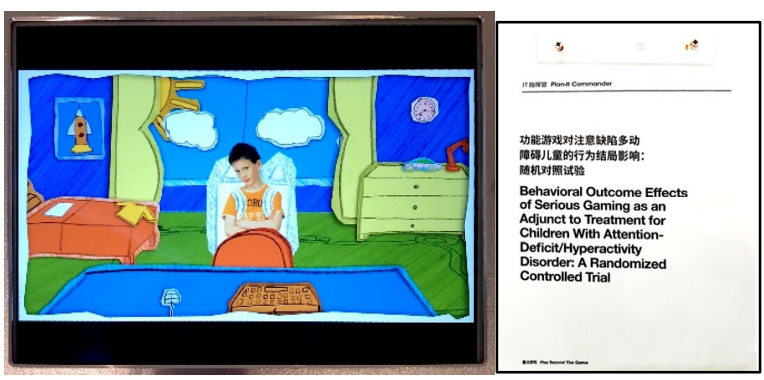

Figure 3: Plan-It Commander Game interface and A Randomized Controlled Trial [The picture is from the exhibition "Play Beyond The Game"]
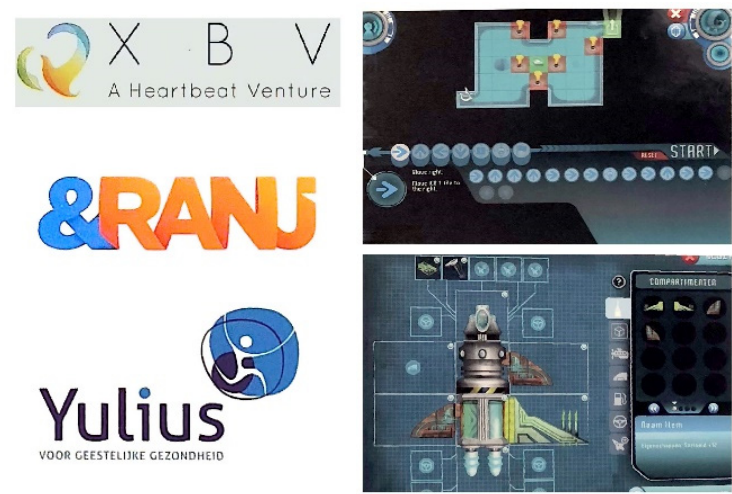

Figure 4: Plan-It Commander Game development team and game interface 


\section{The transformation of narrative style in digital games}

In the study of game narrative mode, it should be different from story and traditional competitive competition. The most significant innovation of video games, compared to traditional board games and sports competitions, is that they place the game within a framework of narrative and fiction.[4] Arseth, founder of Game Science, once pointed out: Narratology and Game Science should be distinguished, if the game as a story to analyze, can not fully understand the connotation and differences between them. There are two common ways to narrative games today: Linear narrative and non-linear narrative. The linear narrative structure is also called "preset narrative." The narrative structure is linear narrative, in the game, the developer first designed the structure and process, the player can only carry out in the established options, and for the design to give the player the right to change the story development line. So it has certain limitation.

Another non-linear narrative (self-narrative). Players have the corresponding leadership right, in a world constructed by many possibilities, according to the rules of the game can choose their own action route, through human-computer interaction to find their own story development line. Such as Animal crossbow developed by Nintendo: New Horizons is designed for a unique experience in the game: "DIY DESIGN" has won the hearts of many players. 《Animal Crossing: New Horizons "players" active creative behavior in the game and social media shows that they are very active in the game narrative processing, fully into the narrative transmission state, and have a deep emotional connection with the game. [5] In the state of narrative transmission, the real world becomes out of reach, and players will have a strong emotional experience due to empathy for the story in the virtual world, and to a certain extent, this experience will change their attitude in real life. [6] There have been comments on "Animal crosswalk: Foreign Studies in New Horizons point out that "Animal Crosstown: The players of "New Horizons" extend a number of different subcomplexes from the preset narrative structure of the game, to a certain extent, the combination of man-machine realizes a unique narrative structure generated by the user's participation, which improves the important composition of the game narrative. This experience not only enriches the game story structure of the game creator, but also improves the player's sense of belonging and loyalty to the game. At present, the narrative mode of the game is gradually optimized, from "competition/fight/attack" to "learning/design/thinking." The change has also inspired the game itself, design and education.

\section{Human care in digital game design}

Serious Game play is very different from the general Game, because it is not pure entertainment as the attraction, but the study of theoretical knowledge or professional skills training as the main content, reflecting the characteristics of the Game, so it shows a very strong educational function. [7] Today, the design of the Serious Game has taken on a new dimension with the development of information technology and has even been given connotations such as psychoanalysis, psychotherapy and cognitive behavioural therapy. With the World Health Organization's inclusion of "Gaming Disorder" in "International diseases." It is not difficult to see that the human care in game design is put on the agenda. Games can not only bring economic benefits, but also make people "Disorder" in the game. As early as the late 20th century, an analysis of game content demonstrated that. Most games contain violent content, and nearly half of them contain "Aggressive violences." In particular, some factors in the game will trigger people's physical and psychological impact. So far, the consideration of health and warning for the game design research to provide a reference.

In Tako Dojo, the 2018 game for children with diabetes by Italian developer Grifo multimedia srl, the protagonist is designed as an adorable little octopus to accompany young patients in their fight against diabetes. The design of the virtual character octopus undoubtedly narrows the distance between the small patient and relieves the pain and pressure of the small player. Virtual characters are graphic entities with life characteristics simulated in Serious games, and virtual characters with credible behavior can improve the user's experience of using Serious games. [8] The goal of the Tako Dojo game is to encourage patients to empower themselves in a relaxed way and to actively manage the disease independently.

Through the tailor-made game mode to play a more comprehensive follow-up, supervision of the daily life of small patients, and formulate the corresponding treatment plan, and finally improve the treatment compliance of small patients and learn to coexist with diabetes in entertainment.

Ready Rufus, a board game designed by Pfizer[British developer], for children with hemophilia, The aim is to change the world of children with hemophilia. The game object is 6-10-year-old children, who can play with siblings and caregivers. Through the game can help small patients to further understand the common sense of disease related to themselves. Because it is a children's game, the rules of the game are relatively simple and easy to operate. The developers also designed the protagonist Rufus as suffering from hemophilia. The game is tailored for children with mild, moderate and severe hemophilia. Through game Ready Rufus, we can improve the understanding of hemophilia and learn to coexist with hemophilia in entertainment. Ready Rufus has worked with many experts in the development process, such as health care professional consultant Dr. Kate Khair (nurse consultant) and child psychologist Perrin Limberg, as well as pediatric nursing expert Amy Jungmann in the Netherlands, hematology nursing expert Shaun Emmit and consulting hematologist Dr. Sarah mangles. In addition, in the development of the game, we also set up a patient Consultant: Matthew minshall, British hemophilia Association / youth diplomatic ambassador, children and their families of British hemophilia Association, active research of game design expert, Alex Tarling, user experience representative, and Professor pamala M. Kato, 
chief game designer; There is also support from the creative agency DDB remedy. A large number of professionals are involved in games for special groups. Although it is in the traditional desktop board game design, it can also greatly reflect the important role of innovative digital technology design for game healing.

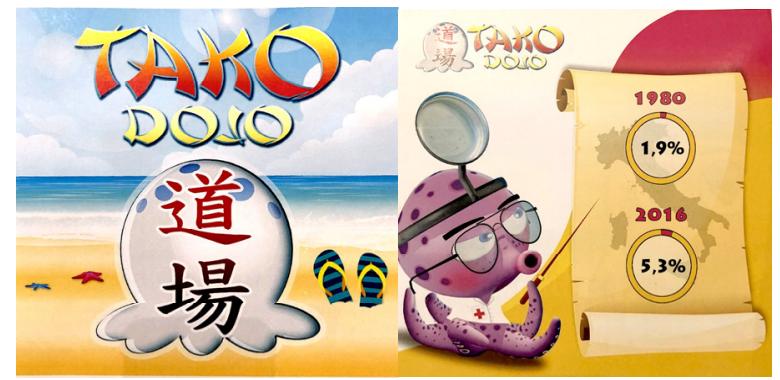

Figure 5: Game: Tako Dojo

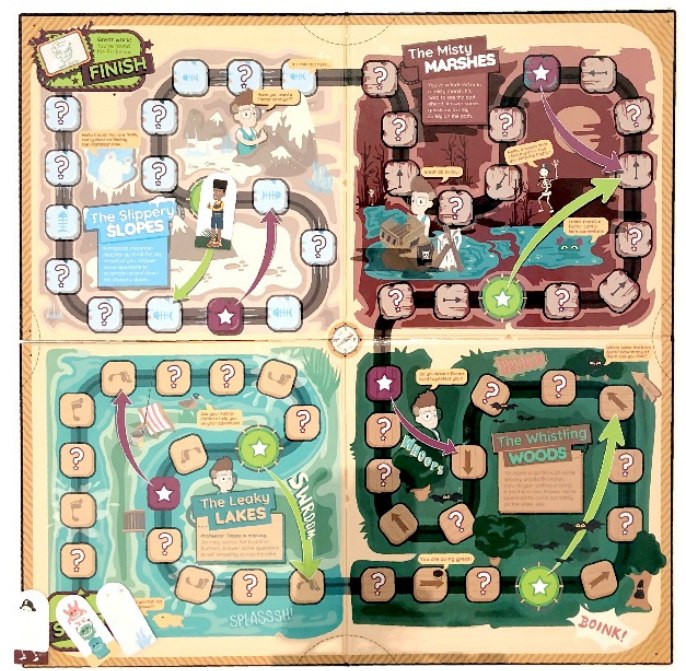

Figure 6: Game: Ready Rufus Game board
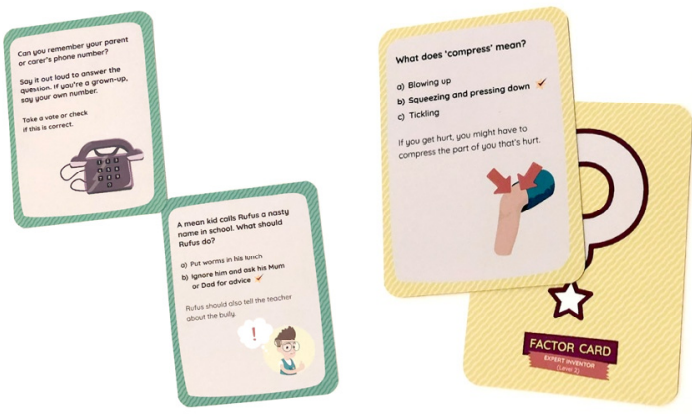

Figure 7: Game: Ready Rufus event card

\section{CONCLUSION}

Modern, highly civilised societies are evolving rapidly, and the multifaceted changes in things, patterns, institutions and environments are not only limited to the human eye, but are increasingly becoming "invisible and real", It has crept into our lives with representative development models and features.[9] Virtual technology facilitates the development of games, which, in addition to bringing great economic benefits, nevertheless should not lose its human dimension. In the digital world, technology realizes the feasibility of Game Technology; in the peoplecentered game world, characters should not lose the temperature of human nature. In the innovative design of functional games for special children, we should grasp the human nature that can not be destroyed in the development of science and Technology. Virtual reality is also a reflection of reality. Reality requires imagination, the way in which human-machine interaction and artificial intelligence intervene, and the way in which the relationship between human and machine is as interdependent and fulfilling as lips and teeth. Science and Technology, as the "middleman" connecting the real world and the virtual world, has strong existence value. So the digital world is more of a valuable reality.

\section{REFERENCES}

1. Feng Tingting. Science fiction, new direction for serious games--the side story of the 2nd Serious Games (Beijing) Innovation Summit[J]. Zhongguancun, 2011, (01) ,76-79.

2. Jiang Hai,Shen Jun. "Game addiction" and healthy coping - and the adaptability of health communication in games, $[\mathrm{J}]$. Journal of Beijing Institute of Technology (Social Science Edition), 2020, (1) ,157163.

3. Zhao Sulei, Wang Le, Zhang Jun, Cui Xiao. Research on the design of serious games based on intangible cultural heritage communication: An example of $\mathrm{Tu}$ Pan embroidery[J]. Decision Exploration, 2020, (9),24-25.

4. Marie-Laure Ryan. The Transformation of Stories [M]. Nanjing: Yilin Publishing House, 2014.

5. Wang Yinan. Cross-media narrative perspectives on game narratives and their implications for educational game development: An example of "Gather round! Animal Mori-kai" as an example[J]. China Electronic Education, 2020, (11),112-118

6. Yan Jin, Yang Shanshan. Persuasive mechanisms of narrative transmission[J]. Progress in Psychological Science, 2013,21(6) ,1125-1132.

7. Deng Daping, Chen Gan, Deng Xiaohong, Xie Xiaoyun, Wei Shouhan. Research and practice of embedding serious games into university classroom teaching in the era of "Internet+"[J]. Education Teaching Forum, 2020, (5) ,242-243.

8. Liu Cuijuan, Liu Zhen, Chai Yanjie, Liu Tingting, Chen Xiaoyi. A review of virtual character behaviour modelling in serious games[J]. Chinese Journal of Image Graphics, 2020, (7), 1318-1329.

9. Kamloops. Constructing the "Tao" dream space of science and technology--the idea of combining VR technology and environmental art design. Education. 2018, (04),93-94. 